\title{
Geräte zur Prüfung der Haftfestigkeit
}

— lcometer hat neue tragbare Haftfestigkeitsmessgeräte auf

— den Markt gebracht. Sie sind einfach zu bedienen, für den Einsatz sowohl vor Ort als auch im Labor geeignet und stehen wahlweise als analoge oder digitale Version für Beschichtungsprüfungen bis 50MPa (7250psi) zur Verfügung.

Durch ihre Bauart wird sichergestellt, dass eine homogene Kraft während des kompletten Messvorgangs durch reibungsloses Drehen der Kurbel auf das Messobjekt ausgeübt wird. Dadurch werden die Wiederholbarkeit der Messergebnisse und eine Genauigkeit von $\pm 1 \%$ gewährleistet.

Mit Hilfe einer Schnellanschlusskupplung können Stempel mit einem Durchmesser von 14,2mm, 20mm oder 50mm einfach befestigt werden. Anhand der Stempel und der Zubehörteile sind Beschichtungsprüfungen auf flachen, gekrümmten, dicken und dünnen Substraten möglich - einschließlich Metall, Holz, Beton und anderen faserigen Materialien.

Der kleine und leichte Prüfkopf (Regler) eignet sich sehr gut für Einhandmessungen auch bei schwer erreichbaren Prüfstücken oder in engen Räumen. Eine gefahrlose Prüfung auf senkrechten Oberflächen wird ebenfalls gewährleistet. Dabei garantiert ein Haftmagnet, dass der Prüfkopf sicher auf der Oberfläche haftet und somit Beschädigungen der Beschichtung verhindert.

Weitere Infos: www.elcometer.de

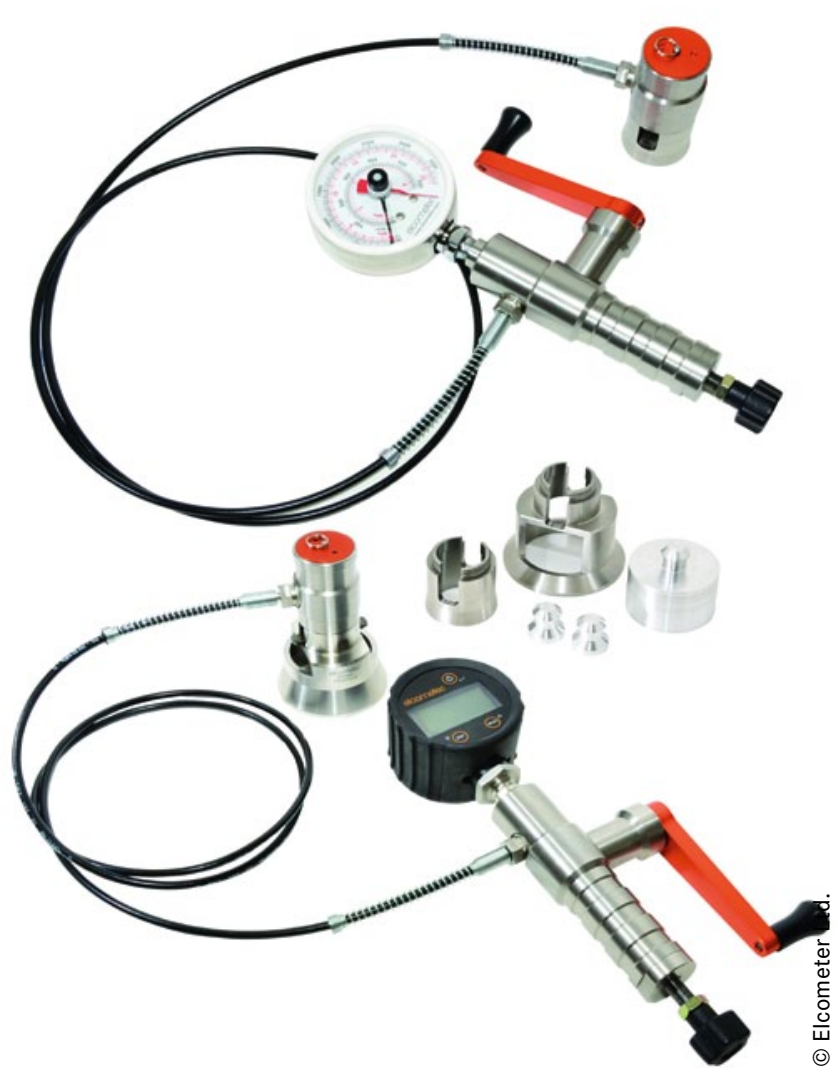

\section{Klebstoff-Navi hilft bei der Auswahl}

$\mathrm{D}$ as Unternehmen Reiff stellt auf seiner Webseite ein sogenanntes Klebstoff-Navi zur Verfügung, das dabei hilft, den jeweils geeigneten Klebstoff für den passenden Einsatzzweck zu finden. Nicht nur im geschäftlichen Bereich findet diese Web-App großen Anklang, sie erleichtert auch den alläglichen Einsatz von Klebstoffen. Das Sortiment der verschiedenen Klebstoffe ist breit gefächert - von Klebstoffen, die eine hohe Temperaturbeständigkeit erfüllen bis hin zu Klebstoffen, die elastische oder schnell fixierende Eigenschaften aufweisen. Das ausgewählte Produkt kann dann bei Bedarf mit einem Klick direkt bestellt werden.

Weitere Infos: www.reiff-tp.de

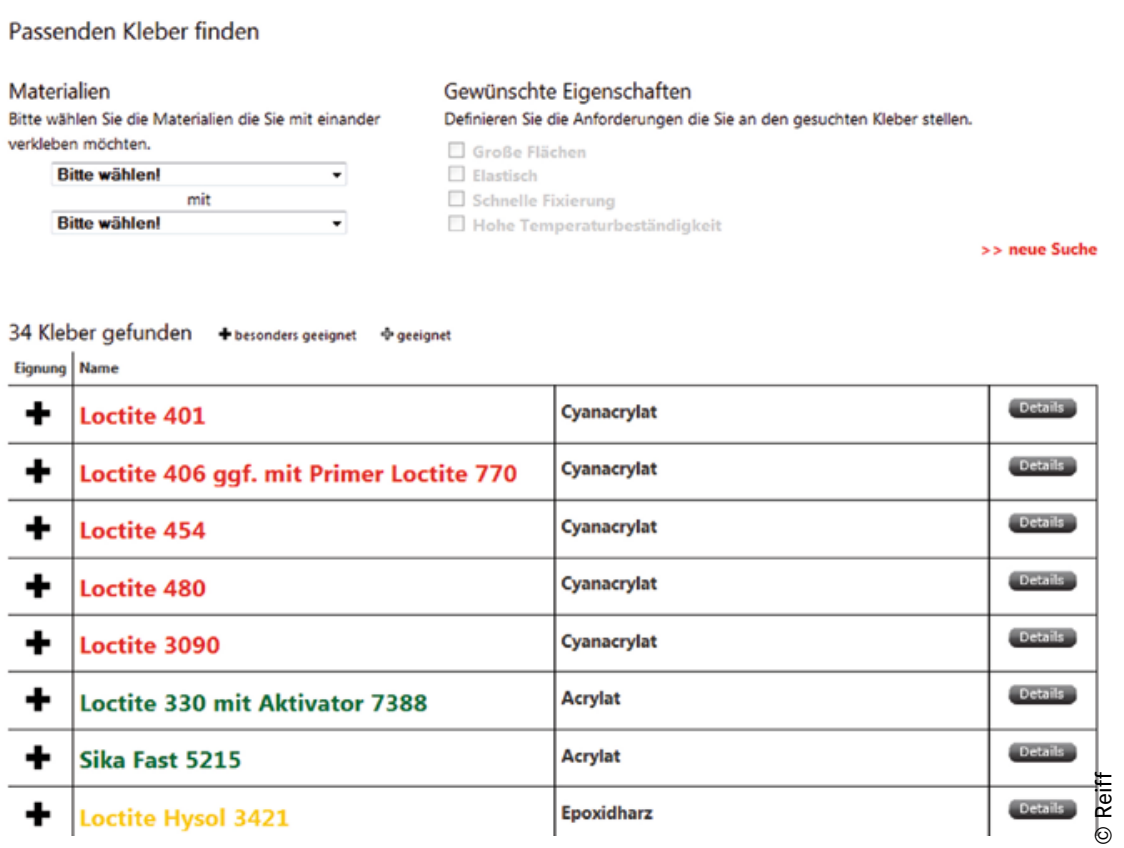

Dieses Klebstoff-Navi soll den Einsatz von Klebstoffen erleichtern. 